\title{
Perceived Complexity of Care, Perceived Autonomy, and Career Satisfaction Among Primary Care Physicians
}

\section{David Katerndahl, MD, MA, Michael Parchman, MD, MPH, and Robert Wood, DrPH}

Background: The purpose of this study was to examine relationships of both perceived autonomy and perceived complexity of care with career satisfaction.

Methods: This secondary analysis used 3 consecutive surveys of family physicians, internists, and pediatricians from the Community Tracking Survey. Two-way analysis of variance assessed interaction effects of perceived complexity of care and perceived autonomy on satisfaction. Logistic regression analysis identified physician characteristics, practice characteristics, practice improvement strategies, perceived complexity, and perceived autonomy that accounted for variance in career satisfaction among physicians.

Results: Although $24 \%$ to $27 \%$ of physicians felt perceived complexity of care expected was greater than it should be, $83 \%$ to $86 \%$ felt free to make clinical decisions. Approximately $80 \%$ of physicians were satisfied with their careers. Differences in probability of career satisfaction were highly significant $(P<.001)$ for both perceived complexity of care and perceived autonomy as well as their interaction. A multiphysician practice; the ability to obtain high quality ancillary services (such as physical therapy, home health care, and nutritional counseling); managed care revenue, lower levels of perceived complexity of expected care; and perceived autonomy were consistently associated with satisfaction.

Conclusion: Higher perceived autonomy and lower perceived patient complexity as higher than desirable were associated with high career satisfaction among primary care physicians. (J Am Board Fam Med 2009;22:24-33.)

Despite the positive impact that primary care has on population health and health care systems, ${ }^{1,2}$ there is a growing shortage of primary care physicians. ${ }^{3}$ Further evidence of this shortage is the observation that specialist physicians are providing primary care services. ${ }^{4}$ Even more alarming is the decline in interest in primary care among graduating medical students. ${ }^{5,6}$

The diminishing numbers of primary care physicians (PCPs) reflect the decreased attractiveness of primary care as a career to new physicians and the loss of established physicians because of retirement and "burnout."7 Recent surveys among US

This article was externally peer reviewed.

Submitted 4 February 2008; revised 8 August 2008; accepted 12 August 2008.

From the Department of Family and Community Medicine, University of Texas Health Science Center at San Antonio.

Funding: none.

Conflict of interest: The corresponding author serves on advisory boards for AstraZeneca and GlaxoSmithKline.

Corresponding author: David Katerndahl, MD, Department of Family and Community Medicine, University of Texas Health Science Center at San Antonio (E-mail: katerndahl@uthscsa.edu).
PCPs found that only $33 \%$ report being very satisfied. ${ }^{8}$ However, US PCPs may be even more satisfied than those from other countries. ${ }^{9-12}$ One explanation for diminishing satisfaction among PCPs may be a decreasing sense of professional autonomy. ${ }^{13}$

PCPs are experiencing a loss of perceived autonomy ${ }^{14}$ possibly because of incentives designed to decrease services and expenses. ${ }^{8}$ This decline in the sense of autonomy is greater among PCPs compared with specialists. ${ }^{13}$ Even though US family physicians rate their ability to order tests as greater when compared with their Canadian counterparts, they also feel that their health care system is more in need of change. ${ }^{12}$ Overall, the situation is so poor for US PCPs that more than half report a sense of powerlessness. ${ }^{14}$

In addition to a loss of perceived autonomy, PCPs are managing patients with much more complex and demanding problems. Patients with multiple chronic illnesses are now the norm, rather than the exception, in primary care clinics. ${ }^{15,16} \mathrm{In}$ addition, guideline-recommended services and treatment regimens for any one chronic disease are 
significantly more complex today than they were a few short years ago. ${ }^{17}$ It is possible that the cognitive and emotional demands placed on PCPs by these types of patients have had an adverse impact on career satisfaction.

The purpose of this study was to examine the relationships of both perceived autonomy and perceived complexity of care with career satisfaction in a nationally representative sample of PCPs. We were primarily interested in these relationships after controlling for physician demographic characteristics and characteristics of the practice environment.

\section{Methods}

\section{Sample}

This study was a secondary analysis of data collected in 3 waves of the Community Tracking Survey (1996 to 1997,1998 to 1999 , and 2000 to 2001); these waves included different participating physicians. Data from the 2004 to 2005 survey were not included because many of the variables differed. The sampling strategy using American Medical Association and American Osteopathic Association files was designed to produce a sample representative of physicians providing direct patient care. ${ }^{18,19}$ Office- and hospital-based physicians who had completed training and provided at least 20 hours of direct patient care weekly were included with PCPs oversampled. Of the original 18,947 eligible physicians in 1996, 12,385 (65\%) were interviewed over the telephone. Item nonresponse rates were generally below $3 \%$.

The Community Tracking Survey used a complex design with 60 sites. Although some physicians completed more than one panel, the public access files used in this survey cannot identify changes in individual physician responses over time. According to study documentation, "it is suitable for most researchers who wish to perform analyses at the national level and do not anticipate using the sitelevel information in their analysis" ${ }^{20}$; site-level information was not used in this analysis. For this study, only PCPs (from family or general practice, general internal medicine, or pediatrics) were used.

\section{Predictors}

Predictors were clustered into 4 groups: (1) physician characteristics; (2) practice characteristics, including the use of practice improvement strategies;
(3) perceived complexity of patients; and (4) physician autonomy.

\section{Physician Characteristics}

Physician variables were selected to identify subgroups who may report differences in satisfaction and included gender; race (white versus nonwhite); salaried (yes/no); specialty (family/general practice, general internal medicine, pediatrics); began practice after 1975 (yes/no) (a proxy for physician age); and the importance of autonomy expectations (very important vs less than very important). Race was only assessed in the 1997 to 1998 and 2000 to 2001 surveys; importance of control of decisions was only assessed in the 2000 to 2001 survey.

\section{Practice Environment}

Practice environment variables were selected that could influence perceptions and included the number of weeks the physician practiced per year, the number of hours per week spent in direct patient care, whether the physician had more than one practice site (yes/no), whether the practice had more than one physician (yes/no), whether there were any nonphysician assistants in the practice (yes/no), and whether the patient population included both adults and children (yes/no). In addition, the percentages of patients with prescription formularies and revenue from Medicaid, Medicare, and managed care were included. Finally, the perceived availability of high-quality ancillary services (such as physical therapy, home health care, and nutritional counseling); imaging; mental health care; and referrals (frequently vs less than frequently) were also included. The presence of nonphysician assistants and care for both adults and children were only assessed in the 1996 to 1997 and 1998 to 1999 surveys, wheras the percentage of patients with a prescription formulary was only assessed in the 2000 to 2001 survey.

\section{Practice Improvement Strategies}

Variables concerning practice improvement strategies designed to improve quality of care but that may have affected perceptions included the perceived effect on the practice (at least moderate vs less than moderate effect) of computer-generated patient data, practice guidelines, patient profiles, reminders, patient surveys, and computer-generated treatment alternatives. The effect of computergenerated patient data and treatment alternatives as 
well as reminders was not assessed in the 2000 to 2001 survey. However, in the 2000 to 2001 survey, 7 questions were asked concerning whether information technology (IT) was used ("no" vs "yes") to get information about treatment alternatives and formularies, to generate reminders, to access patient notes, to write prescriptions, to exchange clinical data, and to communicate with patients. An information technology use scale (IT Uses) was developed consisting of the number of "yes" responses (Kuder-Richardson-20 internal consistency $=0.725)$.

\section{Physician Perceptions}

Perceived complexity of patient care was assessed. Perceived complexity of patient care physicians felt they were expected to provide was measured using the question: "In general, would you say that the complexity or severity of patients' conditions for which you are currently expected to provide care without referral is: much greater than it should be, somewhat greater than it should be, about right, somewhat less than it should be, or much less than it should be?" This variable was dichotomized into "much or somewhat greater complexity of care expected (yes/no)" for use in logistic regression analyses.

Perceived autonomy was measured using the statement "I have the freedom to make clinical decisions that meet my patients' needs," with the responses of "agree strongly," "agree somewhat," "disagree somewhat," "disagree strongly," and "neither agree nor disagree." Perceived autonomy was dichotomized into "agree strongly or somewhat that you have freedom to make clinical decisions (yes/no)."

\section{Outcome}

Career satisfaction was measured using the question, "Thinking very generally about your satisfaction with your overall career in medicine, would you say that you are currently: very satisfied, somewhat satisfied, somewhat dissatisfied, very dissatisfied, neither satisfied nor dissatisfied." Satisfaction was dichotomized into "very or somewhat satisfied with your career (yes/no)."

\section{Analysis}

Data were weighted using the weights provided in the public access file. To assess possible interaction effects between perceived complexity of care and perceived autonomy of the predicted probability of career satisfaction, 2-way analysis of variance was conducted. To identify the relative contributions of physician characteristics, practice characteristics, improvement strategies, and physician perceptions, staged logistic regression analysis was performed for career satisfaction for each survey. Model 1 consisted of physician characteristics only and model 2 consisted of physician and practice characteristics. Model 3 included practice improvement strategies in addition to the physician and practice characteristics. In model 4, the perceived complexity of care and perceived autonomy variables were added to model 3. $\chi^{2}$ statistics were used to assess significance of each model with $P \leq 0.05$ deemed significant. Goodness-of-fit was assessed using Hosmer-Lemeshow statistics and the variance accounted for was estimated using Nagelkerke adjusted $\mathrm{R}^{2}$.

\section{Results}

Table 1 presents the physician and practice characteristics of physicians in this analysis. Physician characteristics were similar across the surveys. Changes in practice characteristics were primarily limited to increases in the number of hours spent in direct patient care and the proportion of revenue from managed care. Overall, $24 \%$ to $27 \%$ of PCPs felt that the perceived complexity of care they were expected to provide was greater than it should be and $83 \%$ to $86 \%$ felt they were free to make clinical decisions. Approximately $80 \%$ of physicians were very or somewhat satisfied with their careers.

\section{Complexity-Autonomy Interaction}

For all 3 panels, the adjusted probability of satisfaction is significantly associated $(P<.001)$ with both perceived complexity of care and perceived autonomy. As Figure 1 demonstrates, physicians who report both low levels of perceived autonomy and high levels of perceived patient complexity are less likely to be very or somewhat satisfied with their career in medicine after controlling for physician, practice environment, and practice improvement characteristics. For example, predicted career satisfaction rose from 55\% among 2000 to 2001 physicians who reported low perceived autonomy and high perceived patient complexity to $86 \%$ among those reporting low perceived patient complexity and high perceived autonomy. 
Table 1. Characteristics of Primary Care Physicians and Their Practices Included in the Three Waves of the Community Tracking Survey

\begin{tabular}{|c|c|c|c|}
\hline Characteristic & $\begin{array}{l}1996-1997 \\
(\mathrm{n}=7197)\end{array}$ & $\begin{array}{l}1998-1999 \\
(n=7264)\end{array}$ & $\begin{array}{l}2000-2001 \\
(\mathrm{n}=7673)\end{array}$ \\
\hline \multicolumn{4}{|l|}{ Physician Characteristics (\%) } \\
\hline Gender (female) & 25 & 29 & 32 \\
\hline Race (white) & - & 77 & 76 \\
\hline \multicolumn{4}{|l|}{ Specialty } \\
\hline Internal medicine & 33 & 33 & 33 \\
\hline Family medicine & 44 & 42 & 43 \\
\hline Pediatrics & 23 & 24 & 24 \\
\hline Began practice (after 1975) & 73 & 79 & 84 \\
\hline Salaried & 53 & 55 & 53 \\
\hline \multicolumn{4}{|l|}{ Practice environment } \\
\hline Number of practices (\% one practice) & 92 & 92 & 92 \\
\hline Weeks practicing in 1995 (mean \pm SD) & $47.8 \pm 2.7$ & $47.8 \pm 2.6$ & $47.7 \pm 2.7$ \\
\hline Hours per week in direct patient care (mean \pm SD) & $42.7 \pm 12.9$ & $42.2 \pm 12.9$ & $44.3 \pm 13.1$ \\
\hline Type of practice (\% solo practice) & 25 & 22 & 22 \\
\hline Number of physicians at practice (mean $\pm \mathrm{SD}$ ) & $26.2 \pm 54.6$ & $26.2 \pm 54.2$ & - \\
\hline Number of assistants (mean \pm SD) & $3.2 \pm 5.8$ & $3.2 \pm 5.8$ & - \\
\hline \multicolumn{4}{|l|}{ Reimbursement } \\
\hline$\%$ Medicaid $($ mean $\pm \mathrm{SD})$ & $15.0 \pm 18.4$ & $15.5 \pm 18.5$ & $15.8 \pm 18.6$ \\
\hline$\%$ Medicare (mean $\pm \mathrm{SD})$ & $27.7 \pm 23.0$ & $27.4 \pm 22.9$ & $27.9 \pm 22.9$ \\
\hline$\%$ Managed Care (mean $\pm \mathrm{SD})$ & $47.5 \pm 28.2$ & $51.0 \pm 27.8$ & $49.4 \pm 27.8$ \\
\hline Cares for both adults and children (\%) & 40 & 39 & - \\
\hline Complexity of expected care (\% greater than it should be) & 24.5 & 24.8 & 27.0 \\
\hline Perceived autonomy (\% having freedom) & 85.8 & 83.5 & 86.2 \\
\hline Career satisfaction (\% satisfied with career) & 80.7 & 80.0 & 79.7 \\
\hline
\end{tabular}

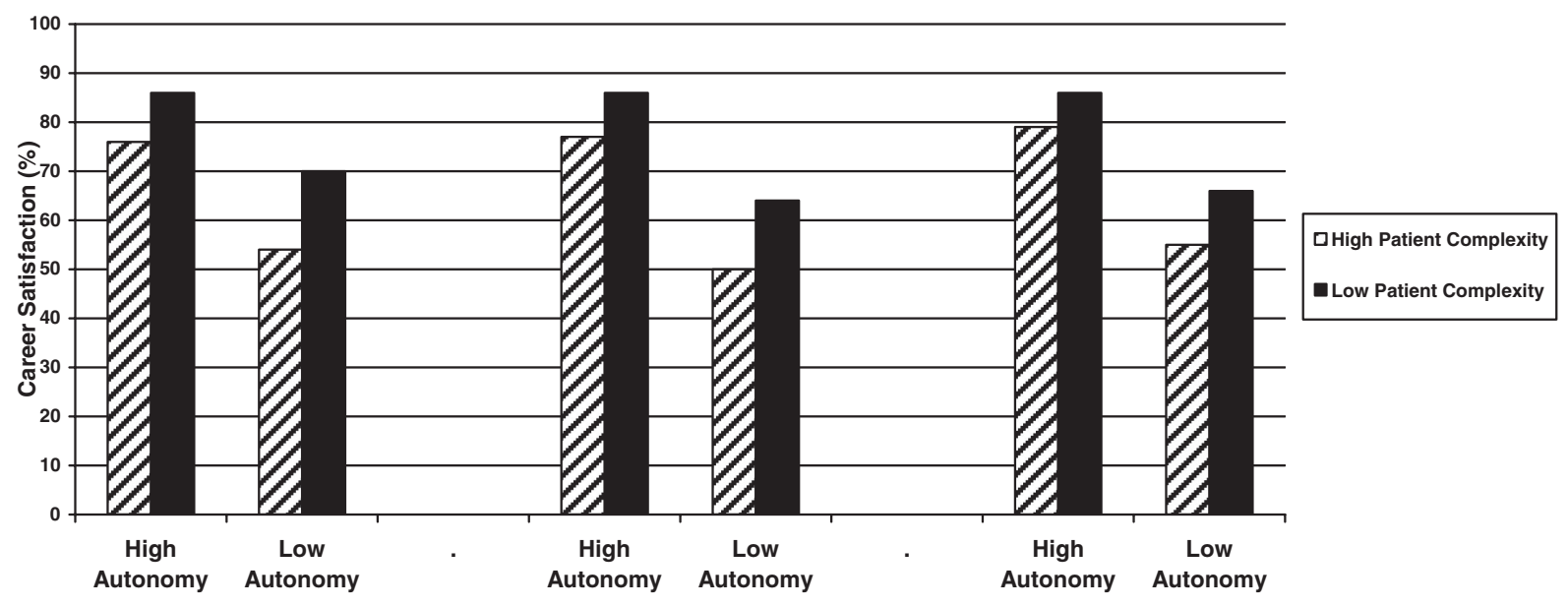

1996-1997

1998-1999

2000-2001

Figure 1. Predicted probability of career satisfaction as interaction between patient complexity and perceived autonomy. 


\section{Correlates of Career Satisfaction}

In each case, practice environment characteristics contributed the most to satisfaction, followed closely by physician perceptions (see Tables 2, 3, and 4). Across all 3 surveys, multiphysician practice; the ability to obtain high-quality ancillary services; lower proportion of revenue from managed care; lower levels of perceived complexity of patients; and perceived autonomy were consistently associated with satisfaction. Although relationships between predictors and satisfaction in the 1996 to 1997 and 2000 to 2001 surveys changed little, the results for the 1998 to 1999 survey included significant associations that were not significant previously, including physician characteristics (race $[\beta,-0.17 ; P=.044]$; internal medicine $[\beta$, $0.78 ; P=.037]$; family practice $[\beta, 0.78 ; P=.036]$, and pediatrics $[\beta, 1.30 ; P=.001])$; practice characteristics (ability to obtain high quality imaging $[\beta$, $0.41 ; P=.010])$; and practice improvement strategies (computer-generated treatment alternatives $[\beta, 0.16$; $P=.038])$.

\section{Discussion}

Although results of the Community Tracking Survey concerning career satisfaction have been reported previously, ${ }^{21,22}$ this analysis is the first to look at the relationships among perceived complexity of care, perceived autonomy, and career satisfaction. In addition to their independent contributions, perceived complexity of care and perceived autonomy significantly interacted to affect the probability of satisfaction. Our analysis found that only multiphysician practice, the ability to obtain high-quality ancillary services, managed care revenue, levels of perceived complexity of patients, and perceived autonomy was consistently associated with satisfaction.

\section{Career Satisfaction}

Overall, approximately $80 \%$ of PCPs expressed satisfaction. This is similar to the results of Baker et $\mathrm{al}^{23}$ among health management organization physicians. None of the analyses in this study found a relationship between satisfaction and physician race, gender, or salary status. This differs from previous studies that found associations with minority status, ${ }^{23}$ gender, ${ }^{7,9,23-25}$ and ownership, ${ }^{21,25}$ employment, ${ }^{25}$ and income. ${ }^{11,21,26}$ Specialty was associated with satisfaction in the older analyses only; Sturm ${ }^{22}$ and Gazewood et $\mathrm{al}^{24}$ found significant differences across specialties. Beginning practice after 1975 (perhaps a proxy for physician age) was an inconsistent predictor, consistent with previous studies., ${ }^{9,11}$

Practice environment variables were more important to satisfaction. Our analyses found that more weeks practicing per year, more hours per week in patient care, and being in a solo practice were significant correlates of lower satisfaction. Previous studies have found that hours spent in patient care, ${ }^{11,24}$ a solo practice, ${ }^{22}$ and the availability of assistants ${ }^{11}$ were significant correlates. The ability to obtain high-quality ancillary services was a consistent predictor of satisfaction. Although revenue from Medicare was an inconsistent predictor, income from managed care was consistently and inversely related to satisfaction. Previous studies have found conflicting results concerning the relationship between managed care and satisfaction, ${ }^{22,24}$ but incentives to reduce services seems to adversely affect satisfaction. ${ }^{8}$

Practice improvement strategies were not related to satisfaction. The use of performance indicators has been felt to decrease perceived autonomy even though some physicians view them as a challenge. ${ }^{27}$ However, the perception that the level of perceived complexity of expected care was greater than it should be was a consistent correlate of dissatisfaction. Although not studied previously, Lin et $\mathrm{al}^{11}$ found that the complexity of claims was associated with dissatisfaction among PCPs.

This study found a consistent association between perceived autonomy and career satisfaction. Not surprisingly, this relationship has been documented previously. ${ }^{21,24-26,28}$ In fact, Baker et $\mathrm{al}^{23}$ found that perceived autonomy was the most important predictor of satisfaction among health management organization physicians. Our study also found considerable overlap among consistent predictors (the ability to obtain high-quality services, the proportion of revenue from managed care, and the perceived complexity of care expected greater than it should be). Previous work found that perceived autonomy was related to financial autonomy,${ }^{14}$ discipline, ${ }^{22}$ solo practice, ${ }^{22}$ and managed care revenues, ${ }^{24}$ perhaps because of the effect of incentives to reduce services. ${ }^{8}$ Thus, these outcomes are related but not identical.

\section{Implications}

Although this study represents 3 cross-sectional, and not causal, analyses, there is reason to consider some to be cause-and-effect relationships. If so, one 


\begin{tabular}{|c|c|c|c|c|}
\hline Variables & $\begin{array}{l}\text { Physician Variables } \\
\text { Only }\end{array}$ & $\begin{array}{c}\text { Physician + Practice } \\
\text { Variables }\end{array}$ & $\begin{array}{l}\text { Physician + Practice } \\
+ \text { Effects Variables }\end{array}$ & $\begin{array}{c}\text { Physician }+ \text { Practice }+ \\
\text { Effect }+ \text { Perception } \\
\text { Variables }\end{array}$ \\
\hline \multicolumn{5}{|l|}{ Physician Variables } \\
\hline Race (white) & $0.259(0.070)^{\S}$ & $0.209(0.079)^{\dagger}$ & $0.183(0.082)^{*}$ & $-0.171(0.085)^{*}$ \\
\hline Gender (female) & $0.000(0.070)$ & $0.010(0.079)$ & $0.009(0.080)$ & $0.061(0.083)$ \\
\hline Salaried & $0.396(0.060)^{\S}$ & $0.097(0.084)$ & $0.110(0.085)$ & $0.108(0.088)$ \\
\hline \multicolumn{5}{|l|}{ Specialty } \\
\hline Internal medicine & $0.609(0.307)^{*}$ & $0.716(0.359)^{*}$ & $0.707(0.360)^{*}$ & $0.775(0.371)^{*}$ \\
\hline Family practice & $0.865(0.306)^{\ddagger}$ & $0.732(0.360)^{*}$ & $0.767(0.362)^{*}$ & $0.782(0.373)^{*}$ \\
\hline Pediatrics & $1.208(0.311)^{\S}$ & $1.276(0.368)^{\S}$ & $1.274(0.370)^{\S}$ & $1.298(0.381)^{\S}$ \\
\hline Began practice after 1975 & $0.291(0.072)^{\S}$ & $0.349(0.082)^{\S}$ & $0.351(0.083)^{\S}$ & $0.331(0.087)^{\S}$ \\
\hline $\begin{array}{l}\text { Importance of control of } \\
\text { decisions (Very Important) }\end{array}$ & - & - & - & - \\
\hline \multicolumn{5}{|l|}{ Practice variables } \\
\hline Weeks practicing per year (n) & & $-0.032(0.014)^{*}$ & $-0.031(0.014)^{*}$ & $-0.021(0.014)$ \\
\hline Hours per week in patient care (n) & & $-0.003(0.003)$ & $-0.003(0.003)$ & $-0.001(0.003)$ \\
\hline Multiple practices & & $-0.221(0.117)$ & $-0.196(0.119)$ & $-0.199(0.123)$ \\
\hline Solo practice & & $-0.211(0.094)^{*}$ & $-0.188(0.095)^{*}$ & $-0.197(0.099)^{*}$ \\
\hline No assistants & & $-0.185(0.078)^{*}$ & $-0.155(0.080)$ & $-0.104(0.083)$ \\
\hline \multicolumn{5}{|l|}{$\begin{array}{l}\text { Frequently obtain high-quality } \\
\text { services }\end{array}$} \\
\hline Ancillary services & & $0.418(0.094)^{\S}$ & $0.419(0.095)^{\S}$ & $0.253(0.099)^{*}$ \\
\hline Imaging & & $0.647(0.142)^{\S}$ & $0.602(0.144)^{\S}$ & $0.406(0.149)^{\dagger}$ \\
\hline Mental health care & & $0.522(0.070)^{\S}$ & $0.531(0.070)^{\S}$ & $0.381(0.073)^{\S}$ \\
\hline Referrals & & $0.405(0.141)^{\ddagger}$ & $0.414(0.142)^{\ddagger}$ & $0.209(0.146)$ \\
\hline \multicolumn{5}{|l|}{ Revenue } \\
\hline From Medicaid (\%) & & $0.002(0.002)$ & $0.002(0.002)$ & $0.001(0.002)$ \\
\hline From Medicare (\%) & & $-0.003(0.002)$ & $-0.004(0.002)^{*}$ & $-0.004(0.002)^{*}$ \\
\hline From managed care (\%) & & $-0.004(0.001)^{\ddagger}$ & $-0.004(0.001)^{\ddagger}$ & $-0.003(0.001)^{*}$ \\
\hline Care for adults and children & & $0.269(0.165)$ & $0.249(0.167)$ & $0.305(0.172)$ \\
\hline Patients with formulary (\%) & & - & - & - \\
\hline \multicolumn{5}{|l|}{ Effect variables } \\
\hline \multicolumn{5}{|l|}{ Moderate effect on practice } \\
\hline $\begin{array}{l}\text { Computer-generated patient } \\
\text { data }\end{array}$ & & & $0.100(0.070)$ & $0.067(0.073)$ \\
\hline Guidelines & & & $-0.129(0.072)$ & $-0.090(0.074)$ \\
\hline Patient profiles & & & $0.025(0.075)$ & $0.066(0.077)$ \\
\hline Reminders & & & $-0.052(0.073)$ & $0.018(0.075)$ \\
\hline Patient surveys & & & $-0.016(0.070)$ & $-0.020(0.073)$ \\
\hline $\begin{array}{l}\text { Computer-generated treatment } \\
\text { alternative }\end{array}$ & & & $0.128(0.075)$ & $0.162(0.078)^{*}$ \\
\hline $\begin{array}{l}\text { Information Technology (IT) } \\
\text { uses (n) }\end{array}$ & & & - & - \\
\hline \multicolumn{5}{|l|}{ Perceptions variables } \\
\hline Expected complexity & & & & $-0.539(0.078)^{\S}$ \\
\hline Perceived autonomy & & & & $1.029(0.081)^{\S}$ \\
\hline$X^{2}(p)$ & $146.93(0.000)$ & $371.54(0.000)$ & $370.72(0.000)$ & $614.67 \quad(0.000)$ \\
\hline$-2 \log \mathrm{L}$ & 7127.1 & 6079.5 & 5968.9 & 5637.2 \\
\hline Hosmer-Lemeshow $\mathrm{X}^{2}(\mathrm{p})$ & $14.26(0.075)$ & $11.48(0.176)$ & $12.35(0.136)$ & $11.20 \quad(0.191)$ \\
\hline Nagelkerke Adjusted $\mathrm{R}^{2}$ & 0.032 & 0.089 & 0.090 & 0.149 \\
\hline
\end{tabular}

All data provided as $\beta$ (SE).

${ }^{*} P \leq .05$.

${ }^{\dagger} P \leq .01$.

${ }^{\ddagger} P \leq .005$.

${ }^{\S} P \leq .001$ 


\begin{tabular}{|c|c|c|c|c|}
\hline Variables & $\begin{array}{l}\text { Physician Variables } \\
\text { Only }\end{array}$ & $\begin{array}{c}\text { Physician }+ \text { Practice } \\
\text { Variables }\end{array}$ & $\begin{array}{l}\text { Physician + Practice } \\
+ \text { Effects Variables }\end{array}$ & $\begin{array}{c}\text { Physician }+ \text { Practice }+ \\
\text { Effect }+ \text { Perceptions } \\
\text { Variables }\end{array}$ \\
\hline \multicolumn{5}{|l|}{ Physician Variables } \\
\hline Race (white) & $0.080(0.071)$ & $0.049(0.080)$ & $0.081(0.083)$ & $0.069(0.085)$ \\
\hline Gender (female) & $-0.024(0.068)$ & $-0.079(0.076)$ & $-0.083(0.077)$ & $-0.077(0.079)$ \\
\hline Salaried & $0.341(0.060)^{\S}$ & $0.056(0.076)$ & $0.049(0.077)$ & $0.022(0.079)$ \\
\hline \multicolumn{5}{|l|}{ Specialty } \\
\hline Internal medicine & $-0.034(0.331)$ & $-0.092(0.379)$ & $-0.076(0.380)$ & $-0.159(0.395)$ \\
\hline Family practice & $0.143(0.331)$ & $0.106(0.378)$ & $0.113(0.379)$ & $0.048(0.394)$ \\
\hline Pediatrics & $0.700(0.336)^{*}$ & $0.732(0.387)$ & $0.759(0.387)^{*}$ & $0.653(0.403)$ \\
\hline Began practice after 1975 & $0.103(0.080)$ & $0.261(0.091)^{\ddagger}$ & $0.243(0.092)^{\dagger}$ & $0.232(0.094)^{*}$ \\
\hline $\begin{array}{l}\text { Importance of control of decisions } \\
\text { (very important) }\end{array}$ & $-0.046(0.066)$ & $-0.078(0.073)$ & $-0.068(0.073)$ & $-0.028(0.075)$ \\
\hline \multicolumn{5}{|l|}{ Practice variables } \\
\hline Weeks practicing per year (n) & & $-0.040(0.013)^{\ddagger}$ & $-0.036(0.013)^{\dagger}$ & $-0.030(0.014)^{*}$ \\
\hline Hours per week in patient care (n) & & $-0.011(0.003)^{\S}$ & $-0.011(0.003)^{\S}$ & $-0.010(0.003)^{\S}$ \\
\hline Multiple practices & & $-0.168(0.118)$ & $-0.171(0.119)$ & $-0.184(0.121)$ \\
\hline Solo practice & & $-0.369(0.084)^{\S}$ & $-0.351(0.085)^{\S}$ & $-0.308(0.087)^{\S}$ \\
\hline No assistants & & - & - & - \\
\hline \multicolumn{5}{|l|}{$\begin{array}{l}\text { Frequently obtain high-quality } \\
\text { services }\end{array}$} \\
\hline Ancillary services & & $0.444(0.094)^{\S}$ & $0.446(0.095)^{\S}$ & $0.267(0.099)^{\dagger}$ \\
\hline Imaging & & $0.284(0.142)^{*}$ & $0.301(0.143)^{*}$ & $0.164(0.147)$ \\
\hline Mental health care & & $0.404(0.070)^{\S}$ & $0.374(0.070)^{\S}$ & $0.270(0.072)^{\S}$ \\
\hline Referrals & & $0.545(0.126)^{\S}$ & $0.564(0.127)^{\S}$ & $0.379(0.132)^{\ddagger}$ \\
\hline \multicolumn{5}{|l|}{ Revenue } \\
\hline From Medicaid (\%) & & $0.003(0.002)$ & $0.003(0.002)$ & $0.003(0.002)$ \\
\hline From Medicare (\%) & & $-0.002(0.002)$ & $-0.003(0.002)$ & $-0.002(0.002)$ \\
\hline From managed care (\%) & & $-0.004(0.001)^{\ddagger}$ & $-0.004(0.001)^{\ddagger}$ & $-0.003(0.001)^{*}$ \\
\hline Care for adults and children & & - & - & - \\
\hline Patients with formulary (\%) & & $-0.001(0.002)$ & $-0.001(0.002)$ & $-0.001(0.002)$ \\
\hline \multicolumn{5}{|l|}{ Effect variables } \\
\hline \multicolumn{5}{|l|}{ Moderate effect on practice } \\
\hline $\begin{array}{l}\text { Computer-generated patient } \\
\text { data }\end{array}$ & & & - & - \\
\hline Guidelines & & & $0.005(0.071)$ & $0.038(0.072)$ \\
\hline Patient profiles & & & $-0.047(0.074)$ & $0.016(0.076)$ \\
\hline Reminders & & & - & - \\
\hline Patient surveys & & & $0.176(0.071)^{*}$ & $0.212(0.073)^{\ddagger}$ \\
\hline $\begin{array}{l}\text { Computer-generated treatment } \\
\text { alternative }\end{array}$ & & & - & - \\
\hline $\begin{array}{l}\text { Information Technology (IT) } \\
\text { uses (\#) }\end{array}$ & & & $0.026(0.018)$ & $0.025(0.019)$ \\
\hline \multicolumn{5}{|l|}{ Perceptions variables } \\
\hline Expected complexity & & & & $-0.437(0.078)^{\S}$ \\
\hline Perceived autonomy & & & & $0.934(0.085)^{\S}$ \\
\hline $\mathrm{X}^{2}(\mathrm{p})$ & $118.04(0.000)$ & $345.96(0.000)$ & $352.36(0.000)$ & $516.59 \quad(0.000)$ \\
\hline$-2 \log \mathrm{L}$ & 7251.3 & 6198.6 & 6108.4 & 5855.8 \\
\hline Hosmer-Lemeshow $\mathrm{X}^{2}(\mathrm{p})$ & $3.69(0.884)$ & $13.54(0.095)$ & $5.84(0.665)$ & $6.88 \quad(0.549)$ \\
\hline Nagelkerke Adjusted $\mathrm{R}^{2}$ & 0.025 & 0.081 & 0.083 & 0.122 \\
\hline
\end{tabular}

All data provided as $\beta$ (SE).

${ }^{*} P \leq .05$.

${ }^{\dagger} P \leq .01$.

${ }^{\ddagger} P \leq .005$.

${ }^{\S} P \leq .001$. 
implication of this analysis is that factors which influence perceived complexity or perceived autonomy will probably influence satisfaction as well. In particular, the ability to obtain high-quality services and minimizing the proportion of revenue from managed care are important factors in maximizing satisfaction. Second, the use of practice improvement strategies had a minimal effect on satisfaction. Although these strategies emphasize the conflict between providing what is best for the illness versus the patient, ${ }^{29}$ they should have little effect on satisfaction. Third, the perception that physicians are expected to provide care at an inappropriately high level of complexity was consistently negatively associated with satisfaction. This is a concerning finding because not only is the complexity of health care increasing, ${ }^{30}$ but this is particularly true of primary care. ${ }^{31}$ In fact, by its very nature, primary care is more complex than specialty care. ${ }^{32}$ To deal with this rise in the perceived complexity of expected care, the PCP must be able to respond with flexible decision making ${ }^{33}$ and creativity. ${ }^{30}$ Generally, combined strategies are required to deal with complex problems. ${ }^{34}$

But at a higher level, what are the implications for keeping PCPs and attracting new physicians into primary care? Whether or not approaches such as practice improvement strategies, managed care, and the use of incentives that limit the availability of services will help control health care costs, perceived autonomy and/or perceived complexity of care being greater than should be are clearly associated with career satisfaction. This is very relevant to the growing crisis of our inability to recruit and keep physicians in primary care. The interaction between low perceived autonomy and high perceived complexity of care creates a situation in which physicians feel they have a lot of responsibility but little authority; it is little wonder that satisfaction would be adversely affected. Yet, the Future of Family Medicine Project has emphasized the need to enhance the attractiveness of family medicine through recognition, resolution of the tension between the need for increased office visits and the provision of quality care, and addressing the challenges posed by managed care. ${ }^{35}$ These issues will inevitably affect the quality and attractiveness of primary care. In addition, because the practice environment of chronic care is unlikely to change, we need to consider ways to better prepare physicians in training to cope with this high-complexity, low-autonomy reality. Through the establish- ment of realistic expectations and improved training in dealing with the realities of practice, physicians may alter their definitions of high-complexity care.

\section{Limitations}

There are several limitations of this study. First, the perceived complexity variables used deal with perceptions of complexity of care; the actual complexity of care was not assessed. In addition, because "complexity is greater than it should be" implies a negative assessment, its relationship to career satisfaction is somewhat circular. Second, the 1996 to 1997 regressions had poor goodness-of-fit statistics, raising concern about the validity of their results. Third, the predictors of career satisfaction accounted for $<15 \%$ of the variance. In fact, for both outcomes, the predictors could not explain most of the variance; there is much more involved in satisfaction and perceived autonomy than what was measured. Fourth, comparing the regressions across surveys is concerning. Not only were different groups of physicians participating in each survey, but some predictors were not assessed in all 3 surveys. The exclusion of results from the 2004 to 2005 survey limits the timeliness of the data. The 2004 to 2005 Community Tracking Survey found that almost $84 \%$ expressed satisfaction (http:// ctsonline.S-3.com/psurvey.asp). Thus, the level of satisfaction among PCPs may be increasing.

\section{Conclusion}

There was considerable interaction among perceived complexity of care, perceived autonomy, and career satisfaction and consistent predictors were identified. Practice variables as well as perceived complexity and perceived autonomy accounted for most of the variance in career satisfaction. If the shortage of PCPs is to be addressed, we must resolve issues surrounding the availability of services, the challenges of managed care, the impact of practice improvement strategies, and the perceived complexity of expected care.

\section{References}

1. Ferrer RL, Hambidge SJ, Maly RC. Essential role of generalists in health care systems. Ann Intern Med 2005;142:691-9.

2. Starfield B, Shi L, Macinko J. Contribution of primary care to health systems and health. Milbank Quart 2005;83:457-502.

3. Donaldson MS, Yordy KD, Lohr KN, Vanselow NA 
(eds). Primary care: America's health in a new era. Washington, DC: National Academy Press, 1996.

4. Fryer GE Jr, Consoli R, Miyoshi TJ, Dovey SM, Phillips RL Jr, Green LA. Specialist physicians providing primary care services in Colorado. J Am Board Fam Pract 2004;17:81-90.

5. Philibert I. Interview with Carl Getto, MD. Accreditation Council for Graduate Medical Education 2004;10-11.

6. Pugno PA, Schmittling GT, McGaha AL, Kahn NB. Entry of US medical school graduates into Family Medicine residencies: 2005-06 and 3-year summary. Fam Med 2006;38:626-36.

7. Kushnir T, Cohen AH, Kitai E. Continuing medical education and primary care physicians' job stress, burnout and dissatisfaction. Med Educ 2000;34:430-6.

8. Hadley J, Mitchell JM, Sulmasy DP, Bloche MG. Perceived financial incentives, HMO market penetration, and physicians' practice styles and satisfaction. HSR 1999;34(1 Part 2):307-21.

9. Garcia-Pena C, Reyes-Frausto S, Reyes-Lagunes I, Munoz-Hernandez O. Family physician job satisfaction in different medical care organization models. Fam Pract 2000;17:309-13.

10. Rout U, Rout JK. Comparative study of occupational stress, job satisfaction and mental health in British general practitioners and Canadian family physicians. Psychology Health Med 1997;2:181-90.

11. Lin HC, Chang WY, Tung YC. Factors related to dissatisfaction with the National Health Insurance among primary care physicians in Taiwan. Chang Gung Med J 2003;26:81-90.

12. Scanlan A, Zyzanski SJ, Flocke SA, Stange KC, Grava-Gubins I. Comparison of US and Canadian family physician attitudes toward their respective health-care systems. Med Care 1996;34:837-44.

13. Burdi MD, Baker LC. Physicians' perceptions of autonomy and satisfaction in Health Aff (Millwood) 1999;18:134-45.

14. Lewis JM, Marjoribanks T. Impact of financial constraints and incentives on professional autonomy. Int J Health Plann Manage 2003;18:49-61.

15. Beasley JW, Hankey TH, Erickson R, et al. How many problems do family physicians manage at each encounter? Ann Fam Med 2004;2:405-10.

16. Starfield B, Lemke KW, Bernhardt T, Foldes SS, Forest CB, Weiner JP. Comorbidity. Ann Fam Med 2003;8-14.

17. Grant RW, Pirraglia PA, Meigs JB, Singer DE. Trends in complexity of diabetes care in the United States from 1991 to 2000. Arch Intern Med 2006;164:1134-9.

18. Kemper P, Blumenthal D, Corrigan JM, et al. Design of the Community Tracking Study. Inquiry 1996;33:195-206.

19. Metcalf CE, Kemper P, Kohn LT, Pickreign JD.
Site definition and sample design for the Community Tracking Study. Washington, DC: Center for Studying Health System Change, 1996.

20. Center for Studying Health System Change. Community Tracking Study physician survey, 1998-1999: ICPSR version. Washington, DC: Center for Studying Health System Change, 2001.

21. DeVoe J, Fryer GE, Hargraves JL, Phillips RL, Green LA. Does career dissatisfaction affect the ability of family physicians to deliver high-quality patient care? J Fam Pract 2002;51:223-8.

22. Sturm R. Effect of managed care and financing on practice constraints and career satisfaction. J Am Board Fam Pract 2002;15:367-77.

23. Baker LC, Bantor JC, Miles EL, Sandy LG. What makes young HMO physicians satisfied? HMO Pract 1994;8:53-7.

24. Gazewood JD, Longo DR, Madsen R. Physician satisfaction with Medicaid managed care. J Fam Pract 2000;49:20-6.

25. Streyffeler LL. A qualitative investigation of the vocational satisfaction of family physicians [dissertation]. The University of Iowa; 2003.

26. Schulz R, Scheckler WE, Moberg DP, Johnson PR. Changing nature of physician satisfaction with health maintenance organization and fee-for-service practices. J Fam Pract 1997;45:321-30.

27. Exworthy M, Wilkinson EK, McColl A, Moore M, Roderick P, Smith H, Gabbay J. Role of performance indicators in changing the autonomy of the general practice profession in the UK. Soc Sci Med 2003;56:1493-504.

28. Buciuniene I, Blazeviciene A, Bliudziute E. Health care reform And job satisfaction of primary healthcare physicians in Lithuania. BMC Fam Pract 2005;6:10.

29. Tinetti ME, Borgardus ST Jr, Agostini JV. Potential pitfalls of disease-specific guidelines for patients with multiple conditions. N Engl J Med 2004;351:2870-4.

30. Plsek PE, Greenhalgh T. Challenge of complexity in health care. BMJ 2001;323:625-8.

31. Stafford RS, Saglam D, Cuasino N, et al. Trends in adult visits to primary care physicians in the United States. Arch Fam Med 1999;8:26-32.

32. Rosen AK, Reid R, Broemeling AM, Rakovski CC. Applying a risk-adjustment framework to primary care. Ann Fam Med 2003;1:44-51.

33. Wilson T, Holt T. Complexity and clinical care. BMJ 2001;323:685-8.

34. Lempert RJ. A new design sciences for complex systems. PNAS 2002;99(Suppl 3):7309-13.

35. Graham R, Bagley B, Kilo CM, Spann SJ, Bogdewic SP. Report of the task force on patient expectations, core values, reintegration, and the New Model of Family Medicine. Ann Fam Med 2004;2(Suppl 1):S33-S50. 